\title{
HEALTH INSURANCE COVERAGE AND THE DISABILITY INSURANCE APPLICATION DECISION
}

\author{
Jonathan Gruber, MIT and NBER \\ Jeffrey Kubik, Syracuse University \\ CRR WP 2002-04 \\ September 2002 \\ Center for Retirement Research at Boston College \\ 550 Fulton Hall \\ 140 Commonwealth Ave. \\ Chestnut Hill, MA 02467 \\ Tel: 617-552-1762 Fax: 617-552-1750 \\ http://www.bc.edu/crr
}

*Jonathan Gruber is a Professor of Economics at the Massachusetts Institute of Technology. Professor Gruber is also a Research Associate at the National Bureau of Economic Research (NBER) and the Director of the NBER's Program on Children. Jeffrey Kubik is an Assistant Professor of Economics at Syracuse University. The research reported herein was performed pursuant to a grant from the U.S. Social Security Administration (SSA) funded as part of the Retirement Research Consortium and to funding from NBER's Center on Aging. The opinions and conclusions are solely those of the authors and should not be construed as representing the opinions or policy of SSA or any agency of the Federal Government or of the Center for Retirement Research at Boston College. The authors thank Stacy Dickert-Conlin and Yun Li for assistance with the SIPP data.

(C) 2002, by Jonathan Gruber and Jeffrey Kubik. All rights reserved. Short sections of text, not to exceed two paragraphs, may be quoted without explicit permission provided that full credit, including (C) notice, is given to the source. 


\title{
About the Center for Retirement Research
}

The Center for Retirement Research at Boston College, part of a consortium that includes a parallel center at the University of Michigan, was established in 1998 through a 5-year \$5.25 million grant from the Social Security Administration. The goals of the Center are to promote research on retirement issues, to transmit new findings to the policy community and the public, to help train new scholars, and to broaden access to valuable data sources. Through these initiatives, the Center hopes to forge a strong link between the academic and policy communities around an issue of critical importance to the nation's future.

\author{
Center for Retirement Research at Boston College \\ 550 Fulton Hall \\ 140 Commonwealth Ave. \\ Chestnut Hill, MA 02467 \\ phone: 617-552-1762 fax: 617-552-1750 \\ e-mail: crr@bc.edu \\ http://www.bc.edu/crr
}

\section{Affiliated Institutions:}

Massachusetts Institute of Technology

Syracuse University

The Brookings Institution

National Academy of Social Insurance

Urban Institute 


\begin{abstract}
We investigate the effect of health insurance coverage on the decision of individuals to apply for Disability Insurance (DI). Those who qualify for DI receive public insurance under Medicare, but only after a two-year waiting period. This raises concerns that many disabled are going uninsured while they wait for their Medicare coverage. Moreover, the combination of this waiting period and the uncertainty about application acceptance may deter those with health insurance on their jobs, but no alternative source of coverage, from leaving work to apply for DI.

Data from the Health and Retirement Survey show that, in fact, uninsurance does not rise during the waiting period for DI benefits; reductions in own employer coverage are small, and are offset by increases in other sources of insurance. Correspondingly, we find that imperfect insurance coverage does deter DI application. Those who have an alternative source of insurance coverage (coverage from a spouse's employer or retiree coverage), are 26 to $74 \%$ more likely to apply for DI than those without such an alternative. Thus, limiting this waiting period would not increase the insurance coverage of the disabled in the U.S., but it would significantly increase applications to the DI program.
\end{abstract}


Disability Insurance (DI), which pays out cash benefits and provides health insurance to those unable to work due to disability, is one of the largest social insurance programs in the United States. In 1998, there were 4.7 million program recipients, on which the government spent $\$ 34.4$ billion in cash benefits and $\$ 23.9$ billion in health care expenditures. DI recipients receive a cash stipend which replaces on average 45 percent of their previous earnings. In addition, after a two year waiting period, they receive health insurance coverage through the Medicare program.

There is a large literature on the incentives for DI application which is reviewed by Bound and Burkhauser (1999). Most of this literature has focused on the impact of cash benefits on the application decision, with other articles examining the impact of the waiting period and the acceptance rate into the program. This literature has generally found that both labor supply and the application decision are sensitive to variation in cash benefits and program stringency, although the behavioral responses are typically modest.

But one key aspect of the DI program which has not been the subject of much study is its health insurance component. For individuals who are disabled, health costs are quite high on average; in 1998, a DI recipient had on average $\$ 4,749$ in Medicare health costs or about $55 \%$ of the average yearly DI cash benefit. The health insurance component of DI is therefore particularly valuable to these disabled individuals. Thus, the availability of health insurance through the DI program, with a delay, could promote application among those with no other source of coverage for their health costs. At the same time, the fact that there is a waiting period, and uncertainty about application acceptance, implies that those who have health insurance that they would lose if they left their jobs to go onto DI will be deterred from application. Moreover, there are important equity issues raised by this arrangement: are many 
disabled individuals going uninsured for long stretches of time because of the Medicare waiting period?

We investigate this important set of issues using the excellent data from the Health and Retirement Survey (HRS). This survey follows a sample of persons born in 1931-1941 for up to ten years (at this point), collecting data on their sources of current and potential health insurance coverage, and their DI application and receipt.

We present two sets of findings that suggest that health insurance plays a very important role in the DI application decision. First, we find that, despite the long waiting period before those on DI receive Medicare coverage, there is no reduction in insurance coverage on net for those applying for or receiving DI. There is only a modest drop in own employer coverage, and this is made up by increased coverage from other sources, so that total insurance coverage actually rises for those applying and initially receiving DI. The implications of these findings are mixed. On the one hand, we clearly document that the waiting period for DI is not causing uninsurance among applicants and recipients. On the other hand, our results imply that individuals who would lose health insurance while waiting for Medicare coverage under DI are deterred from applying for the program.

To further investigate this latter contention, we turn to estimating models of the application decision for DI, as a function of having both own and alternative sources of insurance coverage. As proxies for alternative sources of coverage, we use the presence of either spousal or retiree insurance coverage. We find that, for those who have health insurance, adding an alternative source of insurance significantly increases the odds that they apply for DI. Our estimates imply that those who have an alternative source of insurance should they leave their job, are 26 to $74 \%$ more likely to apply for DI than those without such an alternative source of health insurance. 
Our paper proceeds as follows. Part I provides background on both the DI program and the previous literature on behavioral responses to that program. In Part II we discuss our data and empirical strategy. Part III presents the basic facts on the insurance coverage of DI applicants and recipients. Part IV then presents the results of our models of the DI application decision, along with a host of specification checks designed to illustrate the validity of our results, and an attempt at exploring the welfare implications of our findings. Part V concludes.

\section{Part I: Background}

\section{Disability Insurance Programs in the U.S.}

There are two major sources of income and health insurance for the disabled in the U.S. The largest is the DI program. DI provides insurance for those persons who have an "inability to engage in substantial gainful activity by reason of physical or mental impairment;" this impairment must be medically determinable and last at least 12 months. Eligibility is contingent on previous labor force attachment; most applicants must have worked 20 of the 40 quarters prior to application, although the rules differ somewhat for younger applicants. However, application for DI cannot be made unless the individual has been out of work for at least five months, providing the first of several serious application barriers.

While DI is a federal program with nationally uniform standards, initial awards decisions are made by state DI boards, based on a medical examination. Denied applicants are then entitled to a series of appeals, first to the state agency, then to an Administrative Law Judge who is independent of the state boards, then to an Appeals Council, and finally to the Federal court system. The award 
decision is well known to be a highly imperfect targeting device. In two studies reviewed by Parsons (1991b), reconsideration of initial determinations by either the same review panel one year later or a separate team of medical experts revealed substantial Type I and Type II errors. Overall, current initial acceptance rates for DI applications are 37 percent. Another 13 percent of applicants eventually prevail upon appeal.

The DI benefits for which individuals are potentially eligible are fairly generous. Benefits determination follows the same methodology as Social Security benefit calculations, with benefits computed as a (redistributive) function of past earnings history. After-tax replacement rates averaged approximately $60 \%$ by the mid-1970s (Bound, 1989) and are similar today (Bound and Burkhauser, 1999).

Perhaps as a result of these generous benefits and imperfect targeting, there was a tremendous growth in the DI rolls during the 1960s and 1970s. The number of DI recipients grew from 455,000 in 1960 to 2.8 million by 1977, and total payments grew twentyfold (U.S. Department of Health and Human Services, 1990). At the same time, there was a dramatic decline in the labor force participation rate of older males, and the two time series moved in almost exact parallel, as documented in Parsons (1980).

Another important feature of DI is that it provides health insurance to recipients. After a waiting period of two years after disability, recipients are eligible for coverage under the Medicare program. This is a very valuable benefit for the disabled, given their high medical costs. But it is important to recognize that Medicare is much less generous than the typical employer-provided health insurance policy: there is a $20 \%$ uncapped copayment for physician services, a $\$ 812$ deductible for hospital 
services, and no coverage of prescription drugs, vision care, or dental care.

The other program that provides cash benefits and health insurance to the disabled is the Supplemental Security Income (SSI) program. SSI benefits are available to all disabled, regardless of work history, but they are provided on a means-tested basis. The federal benefit for an individual with no other income is $\$ 545$ per month in 2002. Some states supplement the federal benefit, but, on average, the supplements are small compared to the federal grant.

SSI also provides health insurance. Recipients are immediately eligible for public insurance under state Medicaid programs. Relative to DI, this insurance is much more valuable because there is no waiting period. Moreover, Medicaid is much more generous insurance than Medicare, with almost no copayments or deductibles, and full coverage of prescription drugs, vision care, and dental care in almost all states. ${ }^{1}$ On the other hand, numerous studies have documented that physicians are less willing to accept Medicaid than Medicare patients, so this lowers the value of this alternative source of insurance coverage.

Some state programs can potentially provide health care assistance to individuals applying for DI. About 35 states offer Medicaid coverage to some medically needy individuals; these are people who do not meet the income or resource requirements for Medicaid receipt but who are facing large and disruptive medical expenses. For those not eligible for Medicaid, there are few state programs that

${ }^{1}$ Gruber (forthcoming) discusses the structure of Medicaid in more detail 
provide health care assistance. About a dozen states offer some health care support for those not receiving Medicaid, but most of these programs require there to be a dependent child in the household or have income and resource limits that are only slightly higher than the Medicaid standards.

\section{Gaps in Health Insurance Coverage for Applicants}

Consider an individual who is now covered by health insurance, but who has no source of coverage if they leave their job, and who is considering applying for DI. The structure of DI will deter application by this individual in three ways. First, there is two year waiting period from disability (which is associated with job leaving) to Medicare receipt, during which the individual would be uninsured.

Second, there is the fact that the Medicare coverage available through the DI program is typically much less generous than the private health insurance on the current job. Finally, there is the underlying risk of DI rejection, which occurs in well over half of initial applications. If a new job with health insurance is not immediately available to the rejected applicant, then they may face many years, possibly until age 65, without health insurance. Even if an appeal is successful, the appeal process can take a year or longer, which provides a further waiting period without health insurance.

In the case of SSI application, these barriers are mitigated. There is no waiting period for application, nor is there a waiting period for Medicaid receipt once accepted. The Medicaid insurance that is provided is in theory even more generous than typical private insurance, although limited access to providers mitigates its value. But the last barrier remains: if rejected, the applicant may be left without any coverage. 


\section{Previous Literature on DI and SSI}

There is a large previous literature on the behavioral impacts of disability insurance programs, as reviewed in Bound and Burkhauser (1999). Most of the work in this area has been focused on the impacts of DI cash benefit levels on application and labor supply decisions. There is a wide range of estimated responses to benefit levels, with the most recent evidence (Gruber, 2000) suggesting an elasticity of labor supply with respect to benefits in the range of -0.3 to -0.4. Parsons (1991) and Gruber and Kubik (1997) show that the DI application decision, and labor supply, are also sensitive to the acceptance rate of the system. But there has been little work on the health insurance component of DI.

There has been less work on SSI and the disabled. The most relevant study for our work is that of Yelowitz (1996), who models SSI enrollment as a function of the value of the SSI health insurance benefit. He does so by using variations across states in their SSI Medicaid spending to proxy for the program's generosity, instrumenting average spending on the disabled by spending on blind recipients, a proxy for program generosity that is uncorrelated with the disabled case mix. He finds that growth in Medicaid generosity over 1987-1993 can explain almost all of the substantial growth in the SSI disabled caseload.

\section{Part II: Data and Empirical Strategy}

\section{Data}

Our data source for this analysis is the Health and Retirement Survey (HRS). This is a nationally representative longitudinal survey of the cohort born in 1931-1941. For this cohort, the HRS 
provides data on a variety of demographic characteristics, job characteristics, public program participation information, and disability application data. In particular, the survey asks about (a) health insurance coverage on one's current job, (b) the availability of retiree health insurance coverage, and (c) spousal health insurance coverage.

A key limitation of the HRS for this analysis is that the survey does not ask specifically about application to DI versus SSI. For receipt, we know in which program the respondent is enrolled. But, for application, we know only that he applied to one program or the other.

Our sample for this analysis consists of men younger than age 65 who did not apply for DI or SSI before 1992. Table 1 shows the means of the variables of interest for this full sample, for the sample of those who are applying for DI or SSI and the rest of the sample. Slightly less than 2 percent of the sample applies for DI or SSI during a wave of the HRS. Applicants on average are slightly younger, have less education, are more likely to be unmarried, non-white or Hispanic, and have fewer health insurance and pension alternatives than those who do not apply.

\section{Empirical Strategy}

Our empirical strategy in this paper is twofold. First, we simply present the descriptive statistics on the insurance coverage of those applying for DI. A natural predicate for there to be an important insurance effect on application decisions is that there not be enormous increases in uninsurance among applicants. If many applicants become uninsured when applying for DI, then it suggests that losing insurance cannot be an insurmountable barrier to application. But this also suggests that there are significant inequities arising from the DI waiting period. 
We then turn to modeling the decision to apply for DI as a function of own insurance on the job, and alternative insurance should the person apply for DI. We compare four groups: those with health insurance on their job, but no alternative source of insurance should they leave the job to apply for DI; those with health insurance on the job, and an alternative source of insurance; those without health insurance on the job, and with no alternative source of insurance; and those without health insurance on their job, but with an alternative source of insurance. Relative to those with neither coverage on their job, nor coverage through an alternative source, those who have some alternative coverage should be less likely to apply for DI, since the program is not needed to provide health insurance. But those with own coverage but no alternative source of coverage should be much less likely to apply, since they give up their coverage if they stop work to apply.

We test this set of hypotheses using the following regression specification:

$$
\mathrm{A}_{\mathrm{i}}=\mathrm{a}+\beta_{1} \mathrm{OWNHI}_{\mathrm{i}}+\beta_{2} \mathrm{ALTHI}_{\mathrm{i}}+\beta_{3} \mathrm{OWNHI}_{\mathrm{i}} * \mathrm{ALTHI}_{\mathrm{i}}+\mathrm{X}_{\mathrm{i}} ?+\mathrm{e}
$$

where A is a dummy for application for DI or SSI for individual i, OWNHI is a dummy for own health insurance coverage on the job, ALTHI is a dummy for an alternative source of health insurance coverage, and $\mathrm{X}$ is a set of individual covariates, including: dummies for age, years of education, whether married, whether non-white and Hispanic.

In this regression framework the omitted group is those with no insurance coverage from their own job or any alternative source, and the other three groups are captured by $\beta_{1}$ (those with own health insurance, but no alternative source of insurance), $\beta_{2}$ (those with an alternative source of insurance, but no own insurance), and $\beta_{3}$ (those with both own and alternative insurance). Absent heterogeneity bias, we would predict therefore that $\beta_{1}<\beta_{2}<0<\beta_{3}$, and that $\left(\beta_{1}+\beta_{3}\right)<0$. That is, those with own health 
insurance but no alternative source are least likely to apply; those with alternative coverage but no own coverage are less likely to apply than those with neither; the marginal impact of adding alternative coverage, given that one has own coverage, is to raise the odds of applying; but the overall impact of having own and alternative coverage should be negative relative to having no coverage from any source.

The problem with testing this full set of hypotheses is heterogeneity bias. This regression framework mirrors that used in the "job lock" literature on health insurance-induced immobility, starting with Madrian (1994) and reviewed in Gruber (2001). As that literature discusses at length, the coefficient on own health insurance captures not just impacts of health insurance on mobility (or, in our case, application decisions), but also other unmeasured features of job quality, and unmeasured aspects of the individual's preference for work (and DI receipt). Similarly, the coefficient on alternative health insurance measures other factors correlated with having alternative coverage. If that alternative source is retiree coverage, this may be measuring job quality; if it is spousal coverage, it may be measuring spousal characteristics.

But this literature makes the strong case that the interaction of own and alternative insurance coverage does measure a causal effect. The identification assumption here is a much weaker one, that there is no differential heterogeneity among those with own insurance coverage between those with and without alternative insurance coverage. We will follow this identification assumption. But we will also present a battery of evidence below to demonstrate its validity.

We use two measures of alternative insurance coverage in our analysis. The first, following the job lock literature, is spousal health insurance coverage through work. The HRS collects information on spousal job characteristics, including their health insurance coverage. The second is the availability of 
retiree insurance coverage. Since individuals will be effectively retiring from the labor force when they go on DI, retiree coverage acts as an effective alternative source of insurance coverage during the waiting period before Medicare begins. ${ }^{2}$

There are at least two other potential sources of coverage for individuals applying for DI. The first is the state Medicaid programs described above. As we highlight in that discussion, state coverage is essentially restricted to individuals who are either very low income or have very high medical expenses. In preliminary analysis, we gathered data on the characteristics of all of these state programs, and attempted to model applications as a function of the existence of some state program. But we found no effect in any models of these programs. This likely reflects their highly restrictive nature.

The second is continuation coverage that is mandated under the Consolidated Omnibus Reconciliation Act (COBRA) of 1986. This law mandated that all employers with more than 20 employees provide employees the opportunity to continue to buy their group health insurance for 18 months when they leave their job, at $102 \%$ of the full employer cost of the insurance policy. As discussed in Gruber and Madrian $(1996,1997)$, there are also a host of state continuation laws that

\footnotetext{
${ }^{2}$ We do not have specific information available in the HRS on entitlement ages for retiree health insurance. We assume that any person in our sample who has retiree health insurance is entitled to it. In practice, among those who say that they have retiree health insurance, $88 \%$ report having own employer insurance coverage when they retire, and only $3 \%$ report being uninsured, so our entitlement assumption seems a reasonable one.
} 
provide coverage for a smaller number of months to firms of smaller sizes who do not self-insure their health insurance costs. The impact of continuation coverage is unclear, given its very high costs. We explore this issue further below.

It is important to note once again that our variable represents applications to DI or to SSI. For SSI, the predictions are the same as those laid out above, since there is some chance of rejection when applications are made. But the effects should be much weaker, since there is no waiting period. So our coefficients represent a weighted average of the impacts of DI and SSI incentives.

We estimate all of our regression models as probits. We also correct the standard errors for the fact that we have multiple observations on the individuals in the HRS.

\section{Part III: Descriptive Analysis of Insurance Coverage Among Applicants}

Table 2 shows the pattern of insurance coverage among applicants, in the wave before application, the wave of application, and the wave after application. The results are surprising. From the wave before application to the wave of application, the uninsurance rate actually falls among applicants. This is because the relatively modest $9 \%$ decline in own employer-provided health insurance coverage is more than offset by rises in spousal insurance coverage, Medicare coverage, Medicaid coverage, and other sources of coverage. ${ }^{3}$ The rise in Medicare coverage is due to the fact that the waiting period for Medicare is from the date of disability, not the date of DI application. Of those persons in our sample who report Medicare coverage in the wave of application,

\footnotetext{
${ }^{3}$ Most of this increase comes from private nongroup insurance.
} 
all but one report that they were disabled in the wave before applying.

Tables 3 and 4 show the change in insurance coverage across the waves for those accepted to the DI and SSI programs; for receipt, we can separate these programs. Once again, we see increases, not declines, in insurance for DI recipients in Table 3. The 9 percentage point decline in own employerprovided insurance is fully offset by a 9 percentage point rise in spousal coverage. There is also a $4 \%$ rise in public coverage, and a $5 \%$ rise in other coverage.

The increase in insurance coverage is even larger for SSI recipients. Table 4 shows that this increase is driven almost entirely by a rise in public Medicaid coverage, for which SSI recipients are immediately eligible.

There are a number of surprising features of these results. First, and most importantly, the waiting period for DI does not, on net, seem to cause uninsurance. Second, there is remarkably little decline in own employer-provided insurance among applicants. This is not because applicants are still at work; the employment rate of applicants is $60 \%$ in the wave before application, and only $3.7 \%$ in the wave of application (and $4.2 \%$ in the wave after). We cannot unfortunately distinguish whether this is continuation coverage or retiree coverage. But it is true that roughly $80 \%$ of those in our sample who retain employer coverage when applying for DI report that they have retiree coverage on their job, suggesting that the majority of the retained employer-provided health insurance coverage is retiree coverage.

Third, there is some increase in spousal insurance coverage that is offsetting the loss in own employer coverage. Fourth, there is also some increase in public coverage, although this is small for those on DI (and presumably for those applying to DI). This small amount of public coverage may 
reflect the fact that the waiting period starts when individuals become disabled, not when they apply.

Thus, our main conclusion from this initial exploration of the data is that the process of applying for DI, despite the two year waiting period for Medicare coverage, does not appear to result in widespread uninsurance among applicants. This is a striking finding, and it suggests that individuals are not willing to risk leaving their health insurance behind to apply for DI. We next turn to a regression strategy designed to test this contention.

Given the striking nature of these findings, we pursued confirmatory analysis in another data set, the Survey of Income and Program Participation (SIPP). The SIPP are longitudinal data that follow individuals over a number of waves (four month periods). These data are clearly inferior to the HRS in that we do not know about DI/SSI application, only receipt. But we can find those in the SIPP who begin receiving benefits, then look back in previous waves to see how their health insurance coverage evolves prior to receipt and when receipt begins. The Appendix discusses our analysis and the findings, which completely confirm those of the HRS. In the wave before receipt, and in the first waves after receipt (and thus still during the Medicare waiting period), there is: relatively little decline in own employer-provided insurance; an offsetting rise in spousal insurance, public insurance, and other insurance coverage; and, once again, a decline, not a rise, in uninsurance. Thus, our conclusions here are not driven by particular features of these HRS data.

A distinct question of interest that is not the focus of the current analysis is what happens to rejected DI/SSI applicants. A small literature has explored the outcomes of this group in terms of labor force participation and earnings, and has argued about the interpretation of the findings (see for example Bound, 1991 and Parsons, 1991a). But no one has ever explored the implications for their health 
insurance coverage. While individuals may retain their coverage when applying, if that coverage is lost when they are denied, that could be a significant source of inequity.

In fact, however, as Table 5 shows, there is no rise in uninsurance even among those who are rejected. Their own employer coverage declines, but there is a dramatic increase in spousal coverage, and also some rise in public coverage. The source of the Medicare coverage reported for these individuals is unclear, although these might be people who obtained DI after a lengthy appeal that spanned waves of the HRS and are misclassified in the data set.

\section{Part IV: Regression Analysis}

\section{Basic Results}

Table 6 shows our basic regression results, for our two measures of alternative insurance coverage. We show in each cell the coefficient, the standard error (in parentheses), and the implied marginal effect of a one unit change in the $\mathrm{X}$ variable (in square brackets).

In column (1), we measure alternative coverage using the availability of spousal employerprovided health insurance. In fact, the pattern of estimated coefficients generally matches the predicted pattern discussed earlier. There is a negative effect of both own $\mathrm{HI}\left(\beta_{1}\right)$ and spousal $\mathrm{HI}\left(\beta_{2}\right)$, and the latter is smaller than the former. The first coefficient implies that having own health insurance, but no spousal coverage, lowers the odds of applying for DI by 0.74 percentage points, or roughly $39 \%$ of baseline application rates. The second coefficient implies that having spousal health insurance coverage, but no own coverage, lowers the odds of application by 0.35 percentage points, or roughly $18 \%$ of baseline; this coefficient is not significant. However, as discussed above, we only tentatively interpret 
these as tests of our model, given the underlying differences between those with and without either own or spousal HI.

More compellingly, the interaction of own and spousal $\mathrm{HI}$ is negative and statistically significant. This interaction implies that, for those with own insurance coverage, adding spousal coverage raises the odds of application by $1.1 \%$ relative to having no spousal coverage. This large effect is $58 \%$ of baseline application rates. Moreover, this is even larger than the negative coefficient on own insurance coverage, suggesting that adding an alternative source of coverage more than offsets the negative effects of potentially losing own insurance coverage when one applies for DI. In fact, the sum of $\beta_{1}+\beta_{3}$ is $>0$, rather than $<0$ as predicted, but this sum is certainly not significantly different than zero.

The next column shows the results using a different measure of alternative insurance coverage, retiree insurance. For this measure, there is no need for an interaction, since a necessary condition for having retiree coverage is having own insurance. So, in this model, the question is simply whether the coefficient on retiree coverage is greater than zero. This results in a somewhat weaker test than for spousal insurance, since there is no comparison group without health insurance but with this alternative source of coverage.

And, once again, we find evidence consistent with an important role for insurance in the application decision. The coefficient on own insurance coverage is once again negative, although somewhat smaller than earlier, indicating that own insurance coverage without retiree coverage lowers the odds of DI application by 0.5 percentage points, or $26 \%$ of baseline. But the interaction is positive and marginally significant, and is now almost exactly the same magnitude as the own HI coefficient, so that the two sum to zero. 
In the third column of Table 6, we incorporate both tests into one regression framework. The coefficient on own health insurance (so the effect of having own insurance, but no alternative coverage) is now -0.94 percentage points, or $49 \%$ of baseline. The interaction with both spousal and retiree insurance are positive. The interaction with spousal insurance is about half as large as in column (1), but the interaction with retiree coverage is about twice as large as in column (2). Summing the two coefficients, we find that the availability of any form of alternative coverage raises the odds of DI application by 1.4 percentage points, or $74 \%$ of baseline.

If losing health insurance is indeed a barrier to DI application, then having COBRA coverage should promote applications. Table 7 tests for such a role for COBRA in two ways. First, we simply contrast those who work in large versus small (fewer than 20 employees) firms. Since only the former is protected by federal legislation, we should find that there is a reduced chance of application among those working in small firms that offer health insurance. That is exactly what we see in the first column of Table 7: a negative interaction on small firm with having health insurance. The coefficient is also sizeable, equivalent roughly to the main effect of having own health insurance. But it is highly insignificant.

In the second column of Table 7, we extend the analysis to consider state laws that apply to small firms, using the state laws in place in 1990 from Gruber and Madrian $(1996,1997)$. We create a dummy variable which is one if a person is either in a large firm or a state with a state continuation of coverage law. Here, we expect that if there is a role for COBRA in promoting application, there would be a positive interaction with having health insurance on the job. In fact, there is such a positive interaction, and it is once again sizeable, but once again highly insignificant. We conclude that there is 
simply not enough precision to estimate a role for continuation coverage on the DI application decision, but that the results suggest that such a role may be played by this program.

\section{Specification Checks}

Our key identification assumption in this empirical analysis is that the interaction of own insurance and these alternative insurance sources is exogenous to the decision to apply for DI. In this section, we consider a host of specification checks designed to assess this contention.

We are particularly concerned with the approach of using retiree health insurance to identify these effects. Those who work at firms with retiree health insurance may not be comparable to others with health insurance coverage. In particular, it is possible that those with retiree health insurance also have better pension coverage.

We try to address this possibility in two ways in Table 8 . First, we include in the model a dummy for having pension coverage on the job, and an interaction of that dummy with the health insurance dummy. If retiree coverage is simply picking up pension effects, then the inclusion of this interaction should reduce the importance of the retiree health insurance coefficient.

In fact as shown in column (1), including these controls does not affect the coefficient on retiree health insurance. Having a pension lowers the probability that an individual applies for DI, but there is no significant interaction between having a pension and health insurance. Including these pension controls in column (2) also does not affect the spousal insurance interaction.

But one limitation of this specification check is that it provides a relatively crude parameterization of the pension incentive to retire. It may be that firms with retiree coverage aren't just 
the ones with pensions, but actually the firms with more generous pensions. To address this, we incorporate pension wealth and retirement incentive measures from Coile and Gruber (2000). In that paper, the authors compute both the PDV of pension entitlements ("pension wealth"), but also the dynamic incentives to continue work from pensions ("peak value", or the difference in pension wealth between this year and when it is maximized). So we can include both of these regressors in our model, along with interactions of them with health insurance, to assess whether we are simply finding that firms with retiree health insurance are the ones with "better" pension plans.

In fact, we see no evidence that this is the case. Adding controls for both the PDV and peak value of pensions has no impact on the estimated retiree health insurance coefficient (nor on the spousal insurance interaction). The pension wealth coefficient is actually negative, suggesting that those with better pensions are less likely to apply for DI; this is likely an income effect. The coefficient on the peak value is negative also, suggesting that those with lower pension incentives to continue working are the ones most likely to apply. But there is no significant interaction between either pension variable and health insurance, and including these extra regressors does not in any way alter our conclusions.

The spousal insurance strategy appears more immune to these concerns. But it is still possible that the interaction of spousal insurance with own insurance is somehow correlated with tastes for work. We consider two types of tests to address this concern. First, we include interactions of own health insurance with a host of other characteristics of the spouse and of her job. If our results are simply picking up interactions with spousal quality, and not spousal insurance per se, then they should be weakened when these interactions are included.

In the first and second column of Table 9, we therefore interact own health insurance with 
spouse's age and education. In the third and fourth columns, we also add interactions with spouse's industry and occupation dummies, a dummy for whether the spouse has a pension, and four dummies for the quartiles of spouse earnings distribution. In both cases, we find essentially no effect on our interaction of interest, suggesting that spousal health insurance is not just proxying for spousal quality or spousal job quality. Nor, in either case, is there much effect on the retiree health insurance coefficient.

The second test is to include as well an interaction with whether the spouse has retiree health insurance. Unlike own retiree insurance, spousal retiree health insurance should have little effect on decisions to apply for DI, unless the spouse is planning to retire during the waiting period for Medicare. But this may be a particularly good indicator of heterogeneity, capturing whether we are simply measuring an interaction with spousal job quality rather than a spousal insurance effect per se.

In fact, as we show in the fifth and six columns of Table 9, however, there is no impact of including this interaction on either the spousal health insurance interaction, nor on the retiree health insurance coverage coefficient. Thus, we find no evidence that heterogeneity is driving our findings.

\section{Implications for Health Mix of Applicants}

We have demonstrated that a lack of alternative coverage reduces DI applications among those with own employer coverage. But the welfare implications of this finding depend critically on whose applications are being deterred. Consider two individuals who are contemplating application for DI; individual A is much more disabled than individual B. On the one hand, individual A is more likely to apply regardless of health insurance coverage, since they are less able to carry on working. Moreover, the fact that individual A is more likely to be accepted means that they take a lower risk of 
long run uninsurance through application. On the other hand, individual A presumably has a higher health insurance costs, so that the Medicare waiting period is more costly to them if they do not have an alternative source of coverage. So it is not obvious ex ante whether the waiting period for Medicare, and the risks of rejection, deter applications from the sickest or most healthy applicants.

If the most disabled are applying for DI regardless of health insurance considerations, and it is only the most able applicants who are being deterred, then this suggests that there may be little welfare costs to this application barrier. But if their higher health insurance costs are deterring the most disabled from applying for the program, then there could be "perverse self-selection" along the lines outlined by Parsons (1991b), and there could be significant welfare costs from "locking" the truly disabled into the labor force for fear of losing health insurance during the waiting period.

We assess the implications of health insurance for the health mix of applicants in two ways. First, we take the sample of those who apply for DI, and regress their health status on our insurance measures. If insurance barriers are having a greater effect on those who are more disabled, then we should see that, among applicants who have health insurance, alternative sources of coverage are associated with worse health status on the margin. That is, the applicants who are "unlocked" by alternative sources of coverage are the least healthy.

For this test, we use three measures of poor health: whether an individual reports themselves in poor health; whether the number of ADLs an individual has difficulty performing is in the top $10 \%$ of the distribution; and whether the individual has an unhealthy body mass index (> 34 or $<20)$. In Table 10, we find little consistency in the estimates of the effects of alternative health insurance availability on the health reporting of DI applicants. Given the large standard errors of these estimates, this test does not 
allow us to determine whose application decisions are affected by health insurance considerations.

Our second test is to assess the impact of health insurance coverage on the odds of application success. If it is true that lack of health insurance deters application among the most ill, then we should see that alternative sources of insurance coverage for those who have employer-provided insurance are associated with a higher rate of acceptance among applicants. The results of these estimates are shown in Table 11. Those DI applicants with their own employer-provided health insurance are more likely to be accepted; however, the availability of other sources of insurance lowers the probability of acceptance. Again, though, these results are imprecisely estimated. Thus, we are unable to draw strong conclusions as to the welfare implications of these findings.

\section{Part V: Conclusions}

In 1998, the U.S. government spent almost \$24 billion on the Medicare component of the Disability Insurance program, which is $55 \%$ as large as spending on cash benefits. Moreover, the high cost of medical care for disabled individuals implies that they will greatly value this component of the DI package. Given this, the two year waiting period for Medicare benefits for DI recipients raises two important questions. First, are many individuals going uninsured while they wait for their health insurance coverage? Second, does the waiting period, and the uncertainty about Medicare receipt, deter application among those without alternative sources of insurance coverage?

We find that, in fact, uninsurance falls among those who apply for DI. These individuals see only a modest reduction in employer coverage, which is more than compensated by increased coverage by spousal insurance and public insurance. Thus, there is not widespread uninsurance resulting from the 
waiting period. Indeed, uninsurance even falls among those who are rejected from the program, suggesting that this is not a concern with respect to low program acceptance rates either. We also find that the imperfect insurance coverage for DI applicants does serve to deter application. Those with an alternative source of coverage are 26 to $74 \%$ more likely to apply to the program than those without such an alternative.

These findings have several important welfare implications. First, they suggest that reducing the waiting period or otherwise enhancing the insurance coverage of DI applicants will not do much to increase insurance coverage in the U.S. Rather, it would simply replace private sources of coverage with public coverage.

Second, however, enhancing insurance during the waiting period would promote application to DI. As discussed above, the welfare implications of these increased applications is unclear. If the applications that are promoted are from the marginal applicants who are least disabled, then this might not be a efficacious use of public funds. If, on the other hand, those deterred from applying by the waiting period are the most disabled applicants who cannot bear the risk of going without coverage for any period of time, then there could be major welfare gains from loosening this "application lock". A key priority for future work is to assess the underlying disability of those who are and are not deterred by this important application barrier. 
Table 1: Summary Statistics

Full Sample $\quad$ DI/SSI Applicants Non-Applicants

\begin{tabular}{|c|c|c|c|}
\hline Apply for DI/SSI (\%) & 1.90 & & \\
\hline Age & $\begin{array}{l}57.62 \\
{[4.13]}\end{array}$ & $\begin{array}{l}56.75 \\
{[3.72]}\end{array}$ & $\begin{array}{l}57.64 \\
{[4.13]}\end{array}$ \\
\hline Years of Education & $\begin{array}{c}12.56 \\
{[3.23]}\end{array}$ & $\begin{array}{c}11.06 \\
{[3.35]}\end{array}$ & $\begin{array}{c}12.58 \\
{[3.23]}\end{array}$ \\
\hline Non-White (\%) & 18.26 & 27.72 & 18.08 \\
\hline Hispanic (\%) & 7.94 & 11.31 & 7.87 \\
\hline Married (\%) & 84.12 & 73.03 & 84.34 \\
\hline Own Health Insurance (\%) & 58.89 & 46.82 & 59.13 \\
\hline Spouse Health Insurance (\%) & 44.37 & 35.96 & 44.53 \\
\hline Retiree Health Insurance (\%) & 44.21 & 30.83 & 44.55 \\
\hline Pension $(\%)$ & 69.66 & 52.24 & 70.05 \\
\hline Self-Reported Poor Health (\%) & 3.27 & 13.48 & 3.07 \\
\hline ADL Poor Health $(\%)$ & 10.00 & 23.97 & 9.45 \\
\hline BMI Poor Health (\%) & 7.72 & 9.36 & 7.69 \\
\hline
\end{tabular}

Notes: The entries are means of HRS data set. Standard deviations are in brackets. The number of observations is 14,020 . 
Table 2: Health Insurance Tabulations of DI/SSI Applicants

\begin{tabular}{lccc}
\hline & $\begin{array}{c}\text { Wave Before } \\
\text { Application }\end{array}$ & $\begin{array}{c}\text { Wave Application } \\
\text { Reported }\end{array}$ & $\begin{array}{c}\text { Wave After } \\
\text { Application Report }\end{array}$ \\
\cline { 2 - 4 } & $(1)$ & $(2)$ & $(3)$ \\
\hline Own Employer HI & $47 \%$ & $38 \%$ & $27 \%$ \\
Spouse Employer HI & $5 \%$ & $8 \%$ & $13 \%$ \\
Medicare & $0 \%$ & $4 \%$ & $21 \%$ \\
Medicaid & $3 \%$ & $10 \%$ & $11 \%$ \\
Other & $12 \%$ & $14 \%$ & $19 \%$ \\
\hline None & $33 \%$ & $26 \%$ & \\
\hline \hline
\end{tabular}


Table 3: Health Insurance Tabulations of DI Recipients

\begin{tabular}{lccc}
\hline & $\begin{array}{c}\text { Wave Before } \\
\text { Application }\end{array}$ & $\begin{array}{c}\text { Wave Application } \\
\text { Reported }\end{array}$ & $\begin{array}{c}\text { Wave After } \\
\text { Application Report }\end{array}$ \\
\cline { 2 - 4 } & $(1)$ & $(2)$ & $(3)$ \\
\hline Own Employer HI & $57 \%$ & $48 \%$ & $40 \%$ \\
Spouse Employer HI & $4 \%$ & $13 \%$ & $13 \%$ \\
Medicare & $0 \%$ & $3 \%$ & $33 \%$ \\
Medicaid & $2 \%$ & $3 \%$ & $0 \%$ \\
Other & $11 \%$ & $16 \%$ & $6 \%$ \\
None & $26 \%$ & $18 \%$ & $8 \%$ \\
\hline \hline
\end{tabular}


Table 4: Health Insurance Tabulations of SSI Recipients

\begin{tabular}{lccc}
\hline & $\begin{array}{c}\text { Wave Before } \\
\text { Application }\end{array}$ & $\begin{array}{c}\text { Wave Application } \\
\text { Reported }\end{array}$ & $\begin{array}{c}\text { Wave After } \\
\text { Application Report }\end{array}$ \\
\cline { 2 - 4 } & $(1)$ & $(2)$ & $(3)$ \\
\hline Own Employer HI & $34 \%$ & $26 \%$ & $18 \%$ \\
Spouse Employer HI & $6 \%$ & $3 \%$ & $9 \%$ \\
Medicare & $0 \%$ & $14 \%$ & $23 \%$ \\
Medicaid & $6 \%$ & $29 \%$ & $45 \%$ \\
Other & $14 \%$ & $9 \%$ & $0 \%$ \\
None & $40 \%$ & $20 \%$ & $5 \%$ \\
\hline \hline
\end{tabular}


Table 5: Health Insurance Tabulations of Rejected DI/SSI Applicants

\begin{tabular}{lccc}
\hline & $\begin{array}{c}\text { Wave Before } \\
\text { Application }\end{array}$ & $\begin{array}{c}\text { Wave Application } \\
\text { Reported }\end{array}$ & $\begin{array}{l}\text { Wave After } \\
\text { Application Report }\end{array}$ \\
\cline { 2 - 4 } & $(1)$ & $(2)$ & $(3)$ \\
\hline Own Employer HI & $38 \%$ & $33 \%$ & $26 \%$ \\
Spouse Employer HI & $5 \%$ & $6 \%$ & $16 \%$ \\
Medicare & $0 \%$ & $1 \%$ & $8 \%$ \\
Medicaid & $4 \%$ & $11 \%$ & $6 \%$ \\
Other & $11 \%$ & $14 \%$ & $32 \%$ \\
None & $42 \%$ & $36 \%$ & \\
\hline \hline
\end{tabular}


Table 6: The Effect of Health Insurance Coverage on DI/SSI Application Decisions

(1)

$\begin{array}{lc}-.1948 & -.1326 \\ (.0761) & (.0586) \\ {[-.0074]} & {[-.0050]}\end{array}$

$-.0962$

(.1101)

[-.0035]

Own x Spouse Health Insurance

.2733

$(.1353)$

[.0109]
(2)

(3)

$-.0835$

(.1114)

[-.0030]

.1143

(.0709)

[.0045]

Retiree Health Insurance

.1232

.2421

(.0708)

(.1377)

[.0049]

[.0095]

Notes: The dependent variable is an indicator for whether the individual applied for DI/SSI. The regression specification also includes controls for education, marital status, race and age. Standard errors are in parentheses. They are clustered on individuals. Marginal effects are in brackets. 
Table 7: The Effect of COBRA Coverage on DI/SSI Application Decisions

(1)

(2)

Own Health Insurance Indicator

$-.0688$

$-.2461$

(.0509)

(.4262)

$[-.0021]$

$[-.0095]$

Works for Small Firm Indicator

(.1646)

$[.0108]$

Own HI x Small Firm Indicator

$-.0736$

(.3407)

[-.0028]

Covered by State or Federal Law Indicator

$-.1592$

(.1679)

$[-.0070]$

Own HI x Covered by Law

Notes: The dependent variable is an indicator for whether the individual applied for DI/SSI. The regression specification also includes controls for education, marital status, race and age. Standard errors are in parentheses. They are clustered on individuals. Marginal effects are in brackets. 
Table 8: The Effect of HI Coverage on DI/SSI Application Decisions--Controlling for Pensions

\begin{tabular}{|c|c|c|c|c|}
\hline & (1) & (2) & (3) & (4) \\
\hline Own HI & $\begin{array}{c}-.1298 \\
(.0731) \\
{[-.0048]}\end{array}$ & $\begin{array}{c}-.2024 \\
(.0863) \\
{[-.0077]}\end{array}$ & $\begin{array}{c}-.1694 \\
(.0720) \\
{[-.0061]}\end{array}$ & $\begin{array}{c}-.2193 \\
(.0848) \\
{[-.0081]}\end{array}$ \\
\hline Spouse HI & & $\begin{array}{c}-.0852 \\
(.1109) \\
{[-.0031]}\end{array}$ & & $\begin{array}{c}-.0516 \\
(.1178) \\
{[-.0018]}\end{array}$ \\
\hline Own x Spouse HI & & $\begin{array}{c}.2581 \\
(.1358) \\
{[.0102]}\end{array}$ & & $\begin{array}{c}.2397 \\
(.1444) \\
{[.0092]}\end{array}$ \\
\hline Retiree HI & $\begin{array}{c}.1272 \\
(.0706) \\
{[.0050]}\end{array}$ & & $\begin{array}{c}.1314 \\
(.0748) \\
{[.0051]}\end{array}$ & \\
\hline Pension Indicator & $\begin{array}{c}-.1257 \\
(.0907) \\
{[-.0045]}\end{array}$ & $\begin{array}{c}-.0997 \\
(.0910) \\
{[-.0036]}\end{array}$ & & \\
\hline Own HI x Pension & $\begin{array}{c}.0731 \\
(.1149) \\
{[.0027]}\end{array}$ & $\begin{array}{l}.0838 \\
(.1153) \\
{[.0032]}\end{array}$ & & \\
\hline $\begin{array}{l}\text { Pension Wealth } \\
\text { (x 10000) }\end{array}$ & & & $\begin{array}{c}-.0117 \\
(.0067) \\
{[-.0041]}\end{array}$ & $\begin{array}{c}-.0107 \\
(.0066) \\
{[-.0038]}\end{array}$ \\
\hline $\begin{array}{l}\text { Own HI x Pension Wealth (x } \\
10000)\end{array}$ & & & $\begin{array}{c}.0089 \\
(.0071) \\
{[.0031]}\end{array}$ & $\begin{array}{l}.0072 \\
(.0066) \\
{[.0026]}\end{array}$ \\
\hline
\end{tabular}


Peak Value of Pension (x 10000)

Own HI x Peak Value (x 10000)
$-.1130$

(.0855)

[-.0399]

.0868

(.0887)

[.0306]
$-.0939$

(.0774)

[-.0336]

.0818

$(.0820)$

[.0293]

Notes: The dependent variable is an indicator for whether the individual applied for DI/SSI. The regression specification also includes controls for education, marital status, race and age. Standard errors are in parentheses. They are clustered on individuals. Marginal effects are in brackets. 
Table 9: The Effect of HI Coverage on the DI/SSI Application Decision--Controlling for Spouse Characteristics

\begin{tabular}{|c|c|c|c|c|c|c|}
\hline & (1) & (2) & (3) & (4) & (5) & (6) \\
\hline Own HI x Spouse HI & $\begin{array}{c}.3019 \\
(.1534) \\
{[.0089]}\end{array}$ & & $\begin{array}{c}.2738 \\
(.1552) \\
{[.0072]}\end{array}$ & & $\begin{array}{c}.2755 \\
(.1542) \\
{[.0099]}\end{array}$ & \\
\hline Retiree HI Available & & $\begin{array}{c}.1249 \\
(.0708) \\
{[.0049]}\end{array}$ & & $\begin{array}{c}.1092 \\
(.0714) \\
{[.0039]}\end{array}$ & & $\begin{array}{c}.1418 \\
(.0716) \\
{[.0057]}\end{array}$ \\
\hline $\begin{array}{l}\text { Spouse Age } \\
\text { Interaction }\end{array}$ & Yes & Yes & Yes & Yes & No & No \\
\hline $\begin{array}{l}\text { Spouse Education } \\
\text { Interaction }\end{array}$ & Yes & Yes & Yes & Yes & No & No \\
\hline $\begin{array}{l}\text { Spouse Industry } \\
\text { Interaction }\end{array}$ & No & No & Yes & Yes & No & No \\
\hline $\begin{array}{l}\text { Spouse Occupation } \\
\text { Interaction }\end{array}$ & No & No & Yes & Yes & No & No \\
\hline $\begin{array}{l}\text { Spouse Pension } \\
\text { Interaction }\end{array}$ & No & No & Yes & Yes & No & No \\
\hline $\begin{array}{l}\text { Spouse Earnings } \\
\text { Interaction }\end{array}$ & No & No & Yes & Yes & No & No \\
\hline
\end{tabular}




\begin{tabular}{lllllll}
$\begin{array}{l}\text { Spouse Retiree HI } \\
\text { Interaction }\end{array}$ & No & No & No & No & Yes & Yes \\
\hline \hline
\end{tabular}

Notes: The dependent variable is an indicator for whether the individual applied for DI/SSI. The regression specification also includes controls for education, marital status, race and age. Standard errors are in parentheses. They are clustered on individuals. Marginal effects are in brackets. 
Table 10: The Effect of HI Coverage on the Health Status of Men who Apply for DI/SSI

\begin{tabular}{|c|c|c|c|c|c|c|}
\hline & \multicolumn{2}{|c|}{ Self-Reported } & \multicolumn{2}{|l|}{ ADLs } & \multicolumn{2}{|l|}{ BMI } \\
\hline & (1) & (2) & (3) & (4) & (5) & (6) \\
\hline Own HI & $\begin{array}{c}-.1965 \\
(.2140) \\
{[-.0700]}\end{array}$ & $\begin{array}{c}.0757 \\
(.2596) \\
{[.0272]}\end{array}$ & $\begin{array}{l}-.0863 \\
(.2130) \\
{[-.0315]}\end{array}$ & $\begin{array}{l}-.2315 \\
(.2569) \\
{[-.0824]}\end{array}$ & $\begin{array}{c}-.1405 \\
(.2195) \\
{[-.0364]}\end{array}$ & $\begin{array}{l}-.7152 \\
(.3693) \\
{[-.1780]}\end{array}$ \\
\hline Spouse HI & & $\begin{array}{c}.3347 \\
(.4047) \\
{[.1220]}\end{array}$ & & $\begin{array}{c}-.2621 \\
(.3869) \\
{[-.0922]}\end{array}$ & & $\begin{array}{c}.5875 \\
(.3982) \\
{[.1581]}\end{array}$ \\
\hline Own x Spouse HI & & $\begin{array}{c}-.4582 \\
(.4849) \\
{[-.1560]}\end{array}$ & & $\begin{array}{c}.3754 \\
(.4583) \\
{[.1372]}\end{array}$ & & $\begin{array}{c}.2038 \\
(.5402) \\
{[.0534]}\end{array}$ \\
\hline Retiree HI & $\begin{array}{c}.3353 \\
(.2553) \\
{[.1248]}\end{array}$ & & $\begin{array}{l}.1194 \\
(.2564) \\
{[.0444]}\end{array}$ & & $\begin{array}{c}-.2722 \\
(.2861) \\
{[-.0656]}\end{array}$ & \\
\hline
\end{tabular}

Notes: The dependent variable is an indicator for whether the individual is in poor health. The sample is men who apply for DI/SSI The regression specification also includes controls for education, marital status, race and age. Standard errors are in parentheses. They are clustered on individuals. Marginal effects are in brackets. 
Table 11: The Effect of HI Coverage on Whether DI/SSI Applicants are Accepted

(1)

.2175

(.2466)

[.0866]

Own Health Insurance

Spouse Health Insurance

$-.2519$

(.3492)

$[-.1000]$

Own x Spouse HI

$-.1360$

(.4264)

[-.0541]
(2)

.0409

$(.1900)$

[.0163]

Retiree Health Insurance

$-.1255$

(.2309)

[-.0500]

Notes: The dependent variable is an indicator for whether an individual's application was accepted to DI/SSI. The sample is men who apply for DI/SSI. The regression specification also includes controls for education, marital status, race and age. Standard errors are in parentheses. They are clustered on individuals. Marginal effects are in brackets. 


\section{References}

Bound, John (1989) "The Health and Earnings of Rejected Disability Insurance Applicants," American Economic Review 79, 482-503.

Bound, John and Richard V. Burkhauser (1999) "The Economic Analysis of Transfer Programs Targeted on People with Disabilities," in Orley C. Ashenfelter and David Card, eds., Handbook of Labor Economics, vol 2C. Amsterdam: North Holland.

Coile, Courtney and Jonathan Gruber (2000) “Social Security and Retirement," NBER Working Paper $\# 7830$.

Gruber, Jonathan (2000) “Disability Insurance Benefits and Labor Supply," Journal of Political Economy 108, 1162-1183.

Gruber, Jonathan (2001) "Health Insurance and the Labor Market," in Joseph Newhouse and Anthony Cuyler, eds., Handbook of Health Economics. Amsterdam: North Holland.

Gruber, Jonathan (forthcoming). "Medicaid". Forthcoming in Robert Moffitt, ed., Means Tested Transfer Programs in the U.S. (also available as NBER Working Paper \#7829, August 2000).

Gruber, Jonathan and Jeffrey D. Kubik (1997) "Disability Insurance Rejection Rates and the Labor Supply of Older Workers," Journal of Public Economics 64, 1-23.

Gruber, Jonathan and Brigitte Madrian (1996) "Health Insurance and Early Retirement: Evidence from the Availability of Continuation Coverage," in David Wise, ed., Advances in the Economics of Aging.

Gruber, Jonathan and Brigitte Madrian (1997) "Employment Separation and Health Insurance Coverage," Journal of Public Economics 66, 349-382.

Madrian, Brigitte (1994) "Employment-Based Health Insurance and Job Mobility: Is There Evidence of Job-Lock?" Quarterly Journal of Economics 109, 27-54.

Parsons, Donald (1980) “The Decline in Male Labor Force Participation,” Journal of Political Economy 88, 117-134.

Parsons, Donald (1991a) "Self-Screening in Targeted Public Transfer Programs," Journal of Political Economy 99, 859-876. 
Parsons, Donald (1991b) “The Health and Earnings of Rejected Disability Insurance Applicants: Comment," American Economic Review 81, 1419-1426.

U.S. Department of Health and Human Services (1990) Annual Supplement to the Social Security Bulletin, U.S. DHHS: Washington DC.

Yelowitz, Aaron (1996) "Why Did the SSI-Disabled Program Grow So Much? Disentangling the Effect of Medicaid," Journal of Health Economics 17, 321-350. 


\section{Appendix}

Table A below presents the pattern of insurance coverage among new male DI recipients in the two waves before receipt, the wave of receipt and the wave after receipt in the 1996 SIPP. The waves are spread over four month intervals. DI recipients are identified using the $9^{\text {th }}$ through $12^{\text {th }}$ waves of the SIPP, the waves with a consistent coding for DI receipt. A new DI recipient is defined as those who report DI receipt in a wave but do not report DI assistance in any previous wave. There are 174 new

DI recipients in the SIPP.

We see increases in insurance for DI recipients as they approach the time they receive benefits. The small decline in employer-provided insurance is offset by increases in public insurance. This pattern is very similar to our results using the HRS. The changes across waves are usually smaller using the SIPP data, but the SIPP waves span a shorter time period than the waves of the HRS (four months compared to two years). 
Table A: Health Insurance Tabulations of DI Recipients in 1996 SIPP

\begin{tabular}{lcccc}
\hline & $\begin{array}{c}2 \text { Waves } \\
\text { Before Receipt }\end{array}$ & $\begin{array}{c}\text { Wave } \\
\text { Before Receipt }\end{array}$ & $\begin{array}{c}\text { Wave of } \\
\text { Receipt }\end{array}$ & $\begin{array}{c}\text { Wave After } \\
\text { Receipt }\end{array}$ \\
\cline { 2 - 5 } & $(1)$ & $(2)$ & $(3)$ & $(4)$ \\
\hline Own Employer HI & $49 \%$ & $51 \%$ & $41 \%$ & $43 \%$ \\
Spouse Employer HI & $9 \%$ & $5 \%$ & $13 \%$ & $11 \%$ \\
Medicare & $7 \%$ & $7 \%$ & $12 \%$ & $17 \%$ \\
Medicaid & $5 \%$ & $11 \%$ & $14 \%$ & $8 \%$ \\
Other & & & & \\
None & & & & \\
\hline \hline
\end{tabular}




\title{
RECENT WORKING PAPERS FROM THE CENTER FOR RETIREMENT RESEARCH AT BOSTON COLLEGE
}

\author{
Social Security and the Private Pension System: The Significance of Integrated Plans
} Pamela Perun, July 2002

Pension Reform in the Presence of Financial Market Risk

Barry Bosworth and Gary Burtless, July 2002

Why Some Workers Remain in the Labor Force Beyond the Typical Age of Retirement

John B. Williamson and Tay K. McNamara, November 2001

Planning for Retirement: The Accuracy of Expected Retirement Dates and the Role of Health Shocks

Debra S. Dwyer, September 2001

Retirement Wealth and Its Adequacy: Assessing the Impact of Changes in the Age of Eligibility for Full Social Security Benefits

Catherine P. Montalto, September 2001

The Supplemental Security Income Program and Incentives to Take up Social Security Early Retirement: Empirical Evidence from the SIPP and Social Security Administrative Data

Elizabeth T. Powers and David Neumark, September 2001

Explaining Why So Many Households Do Not Save

Annamaria Lusardi, September 2001

Elderly Labor Supply: Work or Play?

Steven Haider and David Loughran, September 2001

The Trend in Lifetime Earnings Inequality and Its Impact on the Distribution of Retirement Income

Barry Bosworth, Gary Burtless, and Claudia Sahm, August 2001

All working papers are available on the Center for Retirement Research website

(http://www.bc.edu/crr) and can be requested by e-mail (crr@bc.edu) or phone (617-552-1762). 